\title{
TARBAWI
}

Volume 3 No.2, Juli-Desember 2018

p-ISSN : 2527-4082, e-ISSN : 2622-920X

\section{Pengembangan Pendidikan Agama Islam Dalam Pembentukan Karakter \\ Peserta Didik}

Development of Islamic Education in Character Formation Students

\section{Yakub}

immawanyakub@yahoo.co.id |Universitas Muhammadiyah Makassar

\begin{abstract}
Abstrak
Hasil penelitian menunjukan bahwa pengembangan pendidikan agama Islam telah dilakukan oleh SMA Muhammadiyah 6 Kota Makassar dalam pembentukan karakter peserta didiknya. Pengembangan ini dilakukan melalui: Pertama, pengembangan pendidikan agama Islam dipengaruhi oleh faktor konstruksi pendidikan agama Islam, dan implementasinya. Kedua, konfigurasi karakter peserta didik melalui formula sosiologis, psikologis, dan keterpaduan sistem. Ketiga, kontribusi pengembangan pendidikan agama Islam terhadap peningkatan respon masyarakat, peningkatan prestasi peserta didik, dan peningkatan mutu layanan pendidikan.
\end{abstract}

Kata Kunci: Pengembangan, Pendidikan Agama Islam, Pembentukan Karakter, Peserta Didik 


\section{Abstract}

The results showed that the development of Islamic religious education has been carried out bay SMA Muhammadiyah 6 Makassar in shaping the character of their students. The development was done through: First, the development of Islamic religious education was influenced by the construction of Islamic religious education, and implementation. Second, the comfiguration of the character of students through the formula of sociological, psychological, and integration of the system. Third, the development of Islamic religious education contributed to the improvement of public response, an increase in learners' achievements, and improving the quality of education services.

\section{Keywords: Development, Islamic Education, Character Formatian, Students}

\section{PENDAHULUAN}

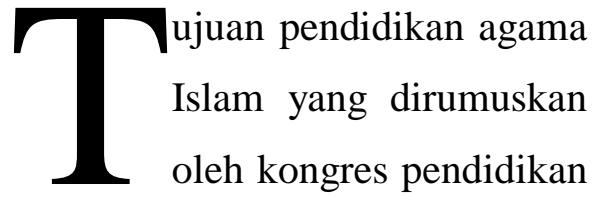

Islam se-dunia adalah seluas dan sedalam kebutuhan hidup manusia sebagai makhluk individual dan sebagai makhluk sosial yang dijiwai oleh ajaran agama. Hal tersebut sejalan dengan pandangan Liam Gearon (2010:185) yang menyatakan bahwa pengajaran kewarganegaraan dapat dilakukan melalui pendidikan agama. Pandangan yang berbeda datang dari L. Broadbent (2002:176) yang menyatakan bahwa pendidikan agama memberikan kontribusi terhadap pembentukan pendidikan kewarganegaraan, dan pendidikan karakter. Demikian pula pernyataannya yang lain bahwa pendidikan agama berkontribusi terhadap pengembangan sosial, budaya, dan kewarganegaraan.
Dalam hal pendidikan agama berkontribusi terhadap pembentukan karakter diakui oleh Muhammad Munir Mursi (1987:54) dengan memberikan penegasan bahwa pendidikan agama dapat mengembangkan intelektual, dan sekaligus pembentukan karakter, pandangan yang sama bahwa pembentukan karakter hingga batas tertentu dipengaruhi oleh moral individu, estetika, sosial dan sentimen keagamaan. Demikian pula pernyataan bahwa pendidikan agama dapat berkontribusi terhadap pengembangan pendidikan dan pengembangan pendidikan dapat mempengaruhi karakter peserta didik. Pernyataan senada pun datang dari $\mathrm{Ki}$ Hajar Dewantara (1962:166) dalam bagian pertama pendidikan berpandangan bahwa pendidikan harus diarahkan pada pembinaan dan pembentukan karakter.

Dualisme bentuk pendidikan populer di Indonesia yaitu pendidikan umum dan pendidikan agama. Pendidikan 
umum membentuk lulusannya unggul dalam bidang pengetahuan dan teknologi, sedangkan pendidikan agama mengambil bentuk lulusannya unggul dalam bidang agama. Namun demikian, Islam memiliki pandangan bahwa pendidikan agama dari jenjang sekolah dasar, menengah sampai perguruan tinggi umum, memiliki urgensi dan signifikansi dalam pembentukan karakter peserta didik yaitu dalam sikap, perilaku keberagamaan peserta didik serta membangun moral dan etika.

Operasionalisasi pendidikan agama Islam yang menjadi core sistem pendidikan di SMA Muhammadiyah 6 Kota Makassar, hal ini sejalan dengan konsep pengembangan pendidikan agama Islam dimana keimanan dan ketakwaan akan menjadi core sistem pendidikan nasional. Hal tersebut dapat direalisasikan apabila rumusannya adalah bahwa pendidikan nasional bertujuan untuk berkembangnya potensi peserta didik agar menjadi manusia beriman dan bertakwa terhadap Tuhan Yang Maha Esa yang berakhlak mulia, sehat, berilmu, cakap, kreatif, mandiri, dan menjadi warga negara yang demokratis serta bertanggung jawab

\section{Gambar. 1}

\section{Pendidikan Agama Islam sebagai Core Sistem Pendidikan}

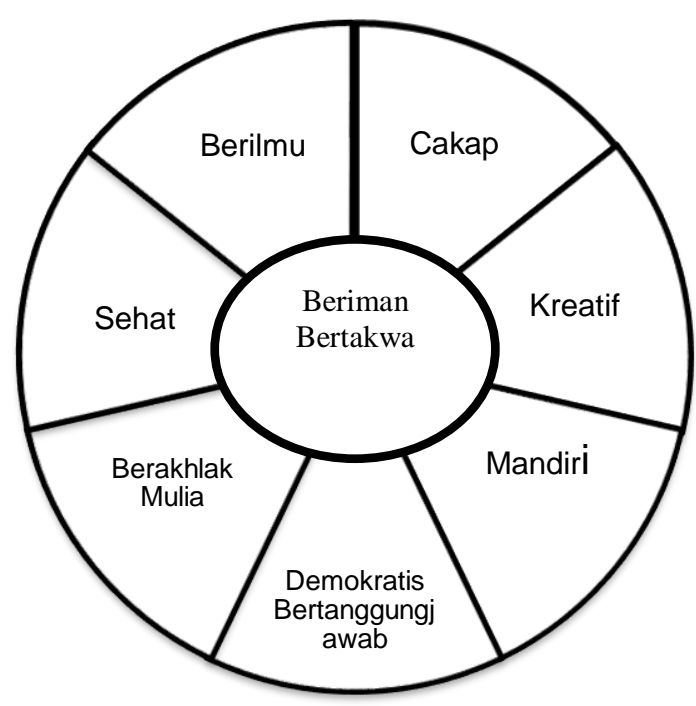

Pandangan tersebut didasarkan pada fungsi dan tujuan pendidikan nasional di Indonesia. Undang-Undang Republik Indonesia Pasal 3 No 20 Tahun 2003 tentang sistem pendidikan nasional (UUSPN) diebutkan bahwa "Pendidikan nasional berfungsi mengembangkan dan membentuk watak serta peradaban bangsa yang bermartabat dalam rangka mencerdaskan kehidupan bangsa, bertujuan untuk berkembangnya potensi peserta didik agar menjadi manusia yang beriman dan bertakwa kepada Tuhan Yang Maha Esa, berakhlak mulia, sehat, berilmu, cakap, kreatif, mandiri, dan menjadi warga negara yang demokratis serta bertanggung jawab,” yang selanjutnya dijabarkan di dalam pengembangan silabus pendidikan agama 
Islam. Hal ini berarti bahwa menurut undang-undang sistem pendidikan nasional tersebut, pendidikan agama mempunyai peranan yang sangat besar dalam pencapaian tujuan pendidikan nasional dan sekaligus rumusan tujuan pendidikan nasional tersebut menjadi dasar dalam pengembangan mutu pendidikan agama Islam dalam pembentukan karakter peserta didik.

Secara makro, sumber pembentukan karakter di antaranya didasarkan pada nilai-nilai ajaran agama. Hal tersebut dikarenakan kehidupan individu, masyarakat, dan bangsa selalu didasarkan pada ajaran agama dan kepercayaannya. Bahkan secara politis, kehidupan bernegara didasarkan pada nilai-nilai ajaran agama. Pada tataran mikro, pembentukkan karakter secara khusus dilaksanakan melalui pendidikan agama Islam, karena misinya adalah mengembangkan nilai dan sikap. Pada pendidikan agama Islam, pembentukan karakter dikembangkan sebagai (instructional effects) dan juga (nurturant effects).

Secara umum pendidikan agama dan keagamaan berfungsi untuk membentuk manusia Indonesia yang berkarakter yaitu beriman dan bertakwa kepada Tuhan Yang Maha Esa serta berakhlak mulia, dan mampu menjaga kerukunan hubungan antar umat beragama, memahami, menghayati, dan mengamalkan nilai-nilai agama yang mengimbangi penguasaannya dalam ilmu pengetahuan, teknologi dan seni. Tujuan pembentukan karakter dalam pendidikan agama lebih rinci menurut Agus Maimun (2003:3) adalah pertama, menanamkan nilai-nilai untuk menangkis pengaruh nilai-nilai negatif atau cenderung negatif akibat arus globalisasi. Kedua, memerangi kecenderungan materialisme, konsumerisme, dan hedonisme. Ketiga, menanamkan pemahaman dan penghayatan nilai keadilan. Keempat, menanamkan etos kerja yang mantap sebagai bekal dalam menghadapi dunia kerja dan realitas sosial.

Namun realita yang terjadi, adanya indikator pendidikan agama termasuk di dalamnya pendidikan agama Islam tidak maksimal mengubah pengetahuan agama yang kognitif menjadi makna dan nilai menjadi afektif yang dapat diinternalisasikan oleh peserta didik, pendidikan agama kurang peka terhadap perubahan sosial, sehingga pendidikan agama Islam tidak banyak berkontribusi terhadap pembentukkan karakter siswa, di antaranya; pertama, fenomena berbagai penyimpangan 
religiusitas di kalangan pelajar, kedua, terjadi pergeseran sistem nilai, ketiga, adanya pengaruh arus deras budaya global yang negatif. Sa'id Agil Husin AlMunawar (2003:41) mengakui hal tersebut, karena pendidikan agama berada pada benteng paling depan dalam menyiapkan sumber daya manusia yang berkualitas bukan hanya kecerdasan akal tapi juga kecerdasan moral dan pendidikan agama seharusnya memberikan kontribusi yang nyata dalam mewujudkan peserta didik yang semakin berkarakter.

\section{METODE PENELITIAN}

Jenis penelitian yang dipakai di dalam penelitian ini, adalah deskriptif kualitatif, dengan pendekatan sosiologis, psikologis dan pendekatan sistem (system approach).

Aspek sosiologis pendekatan fungsional pendidikan Islam dapat digali melalui 2 (dua) hal, yaitu dimensi individual dan dimensi sosial. Secara individual pendidikan Agama Islam memiliki fungsi sebagai penyedia makna (meaning function) dan fungsi identitas (identity function).

Aspek psikologis dapat dijelaskan bagaimana pengembangan pendidikan agama Islam yang meliputi kesadaran beragama (religious counsciousness) dan pengalaman beragama (religiuos eksperience) yang membawa keyakinan yang dihasilkan oleh tindakan (amaliah) meliputi pekerjaan pikiran dan perasaan peserta didik terhadap agama, baik sikap beragama, acuh tak acuh, ataupun anti agama; berarti ungkapan itu adalah proses mental yang mempengaruhi peserta didik sehingga hal tersebut dapat membentuk karakter peserta didik.

Aspek keterpaduan sistem (system approach) dan ciri-ciri yang terkandung di dalam pengembangan pendidikan agama Islam adalah adanya tujuan, adanya komponen sistem adanya fungsi yang menjamin dinamika dan kesatuan kerja sistem dan adanya interaksi antar komponen sistem pendidikan agama Islam.

\section{HASIL DAN PEMBAHASAN}

Hasil temuan penelitian ini berupa 3 (tiga) hal, yaitu: implentasi, konfigurasi, dan kontribusi. Implementasi manajemen pengembangan pendidikan agama Islam SMA Muhammadiyah 6 Kota Makassar dapat digali dari langkahlangkah yang dilakukan oleh sekolah tersebut melalui 3 (tiga) langkah yaitu: konseptualisasi, operasionalisasi, dan institusionalisasi. Demikian pula hasil 
temuan terkait dengan konfigurasi karakter peserta didik dapat digali melalui 3 (tiga) aspek, yaitu: formula sosiologis, psikologis, dan keterpaduan sistem. Selanjutnya hasil temuan kontribusi pengembangan pendidikan agama Islam terhadap peningkatan pendidikan SMA Muhammadiyah 6 Kota Makassar dalam 3 (tiga) hal, yaitu: peningkatan respon masyarakat, peningkatan prestasi peserta didik, dan peningkatan layanan pendidikan tercapai standar capaian mutu pendidikan. Hasil temuan tersebut dapat dikemukakan sebagai berikut:

\section{A. Implementasi Pengembangan \\ Pendidikan Agama Islam}

Implementasi secara konseptual melalui penetapan rencana strategik pengembangan sekolah dan rencana strategik pengembangan penddikan agama Islam, dan penetapan seven velues sebagai identifikasi nilai-nilai karakter penddikan agama Islam terhadap pembentukan karakter. Implementasi pada tataran operasional dapat ditelusuri dengan pengembangan nilai-nilai karakter pendidikan agama Islam yang tercermin dalam bidang kurikulum, kesiswaan, dan sarana prasarana. Selanjutnya implementasi pada tataran institusional dapat dibuktikan melalui penciptaan situasi dan kondisi yang kondusif bagi pengembangan nilai karakter pendidikan agama Islam yang didukung dengan kebijakan dan aturan sekolah, peraturan sekolah dan pelaksanaannya, sarana dan prasarana penunjang, dan sikap dan perilaku kepala sekolah, pendidik, dan tenaga kependidikan.

\section{B. Konfigurasi Karakter Peserta Didik}

Untuk melihat bagaimana karakter peserta didik terbentuk diperlukan formula yang cukup baik, dan pekerjaan ini bukan sesuatu yang mudah. Konfigurasi formulanya adalah berupa aspek sosiologis, psikologis dan keterpaduan sistem. Pengkatagorian nilai didasarkan pada pertimbangan bahwa pada hakekatnya perilaku seseorang yang berkarakter merupakan perwujudan fungsi totalitas psikologis dan totalitas sosial dalam konteks interaksi dan berlangsung sepanjang hayat. Konfigurasi karakter dalam konteks totalitas proses psikologis dan sosial dapat dikelompokkan dalam 3 (tiga) formula, yaitu: formula sosiologis, formula psikologis, dan formula keterpaduan sistem.

Aspek sosiologis berupa kebutuhan individu akan mutu belajar, 
identitas kepribadian, keyakinan, dan pandangan hidup setiap peserta didik berkontribusi terhadap pembentukan karakter peserta didik.

Demikian halnya dengan aspek psikologis berupa kebiasaan beragama individual, dan sosial yang berkaitan dengan ajaran-ajaran agama, kegiatan ibadah baik ritual ibadah (ketuhanan) maupun kemanusiaan, kegiatan-kegiatan yang muncul dari masyarakat sekolah yang beragama, dan suasana kehidupan beragama di lingkungan sekolah seiring kesadaran beragama yang ada di sekolah berkontribusi terhadap pembentukan karakter peserta didik.

Selanjutnya hasil temuan peneliti menunjukan bahwa aspek keterpaduan sistem berupa keterpaduan komponen pendidika agama Islam melalui keterpaduan tujuan, keterpaduan materi, dan keterpaduan proses berkontribusi terhadap pembentukan karakter peserta didik.

\section{Kontribusi}

Pengembangan

Pendidikan Agama Islam dalam Pembentukan Karakter Peserta Didik

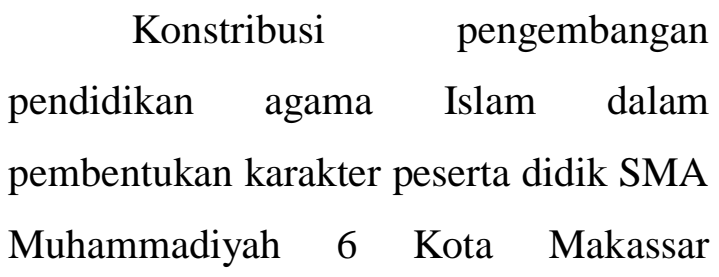

didasarkan pada berkembangnya suatu proses pengejawantahan, dan penanaman nilai-nilai agama Islam secara luas ke dalam setiap aspek kehidupan manusia. Nilai-nilai karakter pendidikan agama Islam peserta didik adalah nilai-nilai karakter agama Islam sebagaimana diterima oleh peserta didik baik di dalam pikiran, perasaan dan tindakannya adalah kontribusi yang sangat berharga dari pengembangan pendidikan agama Islam. Nilai-nilai karakter pendidikan agama Islam inilah yang menjadi kontribusi pengembangan pendidikan agama Islam itu berjumlah 7 (tujuh) nilai-nilai karakter (seven values), dengan rincian sebagai berikut: (1) Integrity attitude (sikap kebanggaan diri); (2) First in islamic moral and academic achievement (unggul dalam moral Islam dan prestasi akademik); (3) Build and maintain friendships (membangun dan menjaga persahabatan); (4) Innovative and creative (kreatif dan inovatif); (5) Respect and trusted (menghormati dan dipercaya); (6) Discipline of self development (disiplin mengembangkan diri); (7) Care and positive contribution to society (peduli dan pengabdian pada masyarakat).

Kontribusi pengembangan penddikan agama Islam terhadap pembentukan 7 
(tujuh) nilai-nilai karakter peserta didik SMA Muhammadiyah 6 Kota Makassar adalah terangkum dalam 3 (tiga) hal, yaitu: Pertama kontribusi sosiologis berupa peningkatan respon masyarakat; Kedua kontribusi psikologis berupa prestasi akademik dan non akademik peserta didik ; dan ketiga kontribusi keterpaduan sistem berupa peningkatan mutu layanan pendidikan hingga tercapai standar dengan nilai 81 pringkat B (Baik) berdasarkan SK penetapan hasil akreditasi BAP-SM nomor 106SK/BAP$\mathrm{SM} / \mathrm{X} / 2015$.

\section{PENUTUP}

Pendidikan agama Islam (PAI) yang dikembangkan, memberikan kontribusi terhadap pembentukan karakter peserta didik. Pengembangan ini dipengaruhi oleh faktor konstruksi pendidikan agama Islam, dan implementasinya. Pembentukan karakter peserta didik tersebut terjadi melalui formula sosiologis, psikologis, dan keterpaduan sistem. Kontribusi pengembangan pendidikan agama Islam berupa peningkatan respon masyarakat, peningkatan prestasi akademik dan non akademik, serta peningkatan mutu layanan pendidikan dengan tercapai standar mutu pendidikan.
Pengembangan pendidikan agama Islam dalam pembentukan karakter peserta didik dicapai melalui konstruksi pendidikan SMA Muhammadiyah 6 Kota Makassar, konstruksinya berupa model lembaga pendidikan hasil transformasi fungsionalisasi Masjid, model sekolah swasta dibawa naungan yayasan Muhammadiyah berkarakter Islam, dan sebuah bentuk lembaga pendidikan Islam yang berkomitmen pada mutu.

Implementasi pengembangan pendidikan agama Islam SMA Muhammadiyah 6 Kota Makassar dapat ditelusuri melalui 3 (tiga) faktor, yakni: konseptualisasi pengembangan pendidikan agama Islam; operasionalisasi pengembangan pendidikan agama Islam; dan institusionalisasi pengembangan pendidikan agama Islam. Konseptualisasi pengembangan pendidikan agama Islam, yaitu dengan penetapan rencana strategis pengembangan sekolah dan rencana strategis pengembangan pendidikan agama Islam. Operasionalisasi pengembangan pendidikan agama Islam dapat dilakukan dengan pengembangan nilai-nilai karakter yang tercermin dalam bidang intrakurikuler, ekstrakurikuler, dan penyiapan sarana prasarana penunjang. Institusionalisasi, strategi 
pengembangan pendidikan agama Islam adalah dengan cara pembentukan institution culture atau school culture (budaya sekolah) yaitu proses internalisasi nilai-nilai karakter pendidikan agama Islam dalam kehidupan sehari-hari. Penciptaan situasi dan kondisi yang kondusif bagi pengembangan nilai karakter pendidikan agama Islam yang dilakukan SMA Muhammadiyah 6 Kota Makassar dengan melalui 4 (empat) komponen, yaitu kebijakan dan aturan sekolah, peraturan sekolah dan pelaksanaannya, ketersediaan dan keterpakaian sarana prasarana pengembangan pendidikan agama Islam, dan sikap dan perilaku kepala sekolah, pendidik, dan tenaga kependidikan

Konfigurasi karakter peserta didik SMA Muhammadiyah 6 Kota Makassar dapat diformulasikan ke dalam 3 (tiga) formula yaitu formula sosiologis, formula psikologis, dan formula keterpaduan sistem. formula sosiologis pembentukan karakter peserta didik dapat dibentuk melalui dalam 4 (empat) aspek, yaitu: pertama, aspek dimensi individual. Kedua aspek identitas atau jati diri. Ketiga, aspek identitas kepribadian, keyakinan, dan pandangan hidup, dan keempat, aspek fungsi struktural. formula psikologis pembentukan karakter peserta didik adalah melalui 3 (tiga) aspek, yaitu pertama, ajaran agama Islam yang meliputi individual, dan sosial, Kedua, kegiatan ibadah baik ritual ibadah (ketuhanan) maupun kemanusiaan dan Ketiga, suasana kehidupan beragama di lingkungan sekolah seiring kesadaran beragama yang ada di sekolah. formula keterpaduan sistem pendidikan Islam melalui 3 (tiga) asprek, yaitu: Pertama, keterpaduan tujuan, kedua, keterepaduan materi, dan ketiga, keterpaduan proses. Ketiga formula tersebut membentuk konfigurasi seven values atau nilai-nilai karakter peserta didik SMA Muhammadiyah 6 Kota Makassar.

\section{DAFTAR PUSTAKA}

Maimun, Agus. Profil Pendidikan Agama Islam (PAI) Model Sekolah Umum Tingkat Dasar. Jakarta: Depag RI Dirjen Kelembagaan Agama Islam Direktorat Madrasah dan Pendidikan Umum Proyek Pemberdayaan Kelembagaan dan Ketatalaksanaan Pada Madrasah dan PAI pada Sekolah Umum Tingkat Dasar, 2003.

Al-Munawar, Sa'id Agil Husein. Aktualisasi Nilai-nilai Qur'an Dalam Sistem Pendidikan Islam. Jakarta: Ciputat Press, 2003. 
Gearon, Liam. Citizenship Making Links WithReligius Education,Learning to Teach Citizenship in The Secondary School. Canada: Routledge, 2010.

Republik Indonesia. Undang-Undang RI Nomor 20 Tahun 2003 tentang Sistem Pendidikan Nasional. Jakarta: Sinar Grafika, 2011.
Broadbent, L. Issues in Religious Education. London: Routledge Falmer, 2002.

Munir Mursi, Muhammad. Al-Islamiyah Usuluha wa Tatawwuruha fi alArabiyah. Kairo: Dar al-Ma'arif, 1987.

Dewantara, Ki Hajar. Bagian Pertama Pendidikan. Yogyakarta: Majelis Luhur Persatuan Taman siswa, 1962. 